\title{
Change Management as a Critical Success Factor in e-Government Implementation
}

\author{
Janja Nograšek \\ University of Ljubljana, Faculty of Administration, \\ Institute for Informatization of Administration, \\ Gosarjeva 5, 1000 Ljubljana, Slovenia \\ janja.nograsek@fu.uni-lj.si
}

\begin{abstract}
Change management in e-government implementation is a very complex issue. E-government services are frequently distributed over different IT systems and organizations. There are also events from outside the public administration that cause changes such as government policies and legislation, public-private partnership, etc., and finally a huge resistance to change exists in public administration proverbial. Another problem is that the e-government is predominantly seen only as a technology mission and not as an organizational transformation issue. Those are probably the main reasons that the existing literature about change management in e-government is still missing at large. There are articles dealing with some aspects of changes affected by the new technology implementation, however, there is no comprehensive framework that would identify changes that have to be managed in e-government implementation. Therefore, the main aim of the paper is to identify a comprehensive set of changes that have to be considered in e-government implementation and the role of leadership in such processes. Finally, the paper proposes a conceptual model of change management in e-government implementation.
\end{abstract}

Keywords: change management, e-government, new leadership style, change management model of e-government implementation

Received 15 July 2011

Revised 28 September 2011

Accepted 25 October 2011

JEL Classification: M 10, M15, O30

\section{Introduction}

Heeks (2000) asked the question "Will ICT help reinvent government? It might, but only if it is correctly managed." Hence, managing changes that are caused by information-communication technology (hereinafter ICT) implementation in government became an important issue in e-government research. Otherwise, not so important that we could speak about the plethora of the literature on change management in e-government. Moreover, we could even speak about deficiency of the literature addressing such issue. Although relationships between technology and organisational changes in public sector have become the subject of increasingly intensive research within the last decade, we could say that there is not clear which the changes that have to be managed in e-government implementation process are. Authors dealing with such relationships examine only one or maybe two aspects of changes that are caused in e-government implementation, e.g. processes, organizational structure, people, organizational culture, etc. No comprehensive set of changes exists there that has to be considered before or in the phase of e-government implementation.

In our paper, we would try to identify set of changes that have to be addressed in e-government implementation. We would limit only on the changes that have occurred inside of public sector organizations, although we are aware of the fact that managing changes of e-government is a very complex task, and that organizational changes may be triggered by events from outside the public administration such as globalization, pressure of good governance, stakeholders needs, new technology, the e-platform, governments policies and legislation, public-private partnership over which public administration has little or no control. Such changes we would try to identify through Leavitt's organizational model that illustrates an organization as a system of people, structure, tasks, and technology. We would also emphasize the role of leadership in e-government as a critical success factor of change management in e-government implementation. After all discussion and review of existing literature of change management in e-government, we propose a conceptual model of change management in e-government implementation which may be a good framework for more successful e-government implementation in the future as there is acknowledged that poor change management strategy is one of the causes why success rate of e-government projects is dismal.

The paper is organized as it follows: in chapters 2 and 3 , we present some basic definitions and concepts of change management and e-government, chapter 4 is literature review about change management in e-government implementation; in the next chapter we identify changes that have to be managed in e-government implementation, then we present the role of e-government leadership in change management and after all discussion we finally proposed new conceptual model of change management in e-government implementation; in the conclusion we summarize the main findings. 


\section{Change management}

Change management is a structured approach to transitioning individuals, teams, and organizations from the current state to the desired future state (Sacheva, 2009, p. 109). It is an organizational process aimed at empowering employees to accept and embrace changes in their current business environment (Hiatt, 2010). Change management has been widely acknowledged as a critical success factor in software systems (Apostolou, Mentzas, Stojanovic, Thoenssen and Pariente Lobo, 2011).

Change management can be reactive, i.e. responding to changes in the macro environment, proactive in order to achieve the desired goal, continuous basis, or programby-program basis, i.e. ad-hoc basis (Sacheva, 2009).

In the context of organizational change, change management consists of a hard side and a soft side. The hard side refers to the processes, systems, strategies, tactics, and technologies that will help to implement changes and the soft side involves behavioral and attitudinal changes (e.g. persuading, reassuring and communicating, identifying and addressing emotional reactions, influencing and motivating) that will allow the hard changes to be successful (Dias de Lima, 2009).

Since the late 1970s, there have occurred a number of change management models. James Prochaska and Carlo DeClemente of the University of Rhode Island have developed the Stages of Change Model in the late 1970s that identifies six stages whereby change occurs, i.e. pre-contemplation, contemplation, preparation/ determination, action/willpower, maintenance and relapse. McKisey 7S Model based on 7S of shared values, a strategy, a structure, a system, staff, a style and skills. All seven elements are required for a complete change (Sacheva, 2009). Lewin's Change Model (1951) identifies three stages of change that are widely used today - unfreezing, effecting change, and refreezing. Kotter's Eight-step Model contains eight steps of change: increase urgency for change, ensure there is a powerful change group to guide the change, develop a vision, empower the staff, ensure there are shortterm wins, consolidate gains and embed the change in culture (Bosilj-Vukšić, 2011). Prosci in 2006 developed five-step AKDAR Model that constitutes the following: awareness of the need to change, desire to participate and support to change, knowledge of how to change, ability to implement the change on a day-to-day basis, and reinforcement to keep change in place. The last model describes five discrete stages, a process by which people allegedly deal with grief and tragedy and is known as Kuble-Ross Model (1999). These stages are known as the Five Stages of Grief: denial, anger, bargaining, depression and acceptance (Sacheva, 2009).
From a number of models how to manage change, we can conclude that managing change is not an easy task. Bosilj-Vukšić (2011) argues: "There is no one right way, but there are a number of frameworks within you can find a way that is right for your change today."

\section{E-government}

Economic and social development in every country is heavily dependent on the development of the public administration. In order to provide better services to businesses and citizens, in the last decade most governments invested in the development of electronic government, shorter e-government. We can find numerous and different definitions of e-government in the literature. E-government is often broadly defined as encompassing all uses of ICT within public administrations and government agencies and units (Beatlle, Waksberg and Aibar, 2009). The European Commission (COM, 2003) defined e-government as the use of ICT combined with organizational change and new skills in order to improve public services and democratic processes and public policies. Grant and Chau (2005, op. cit.: p. 9 in Jansen, 2005) see e-government as "a broadbased transformation initiative, enabled by leveraging the capabilities of information and communication technology: (1) to develop and deliver high quality seamless, and integrated public services; (2) to enable effective constituent relationship management; and (3) to support the economic and social development goals of citizens, businesses, and civil society at local, state, national, and international levels". OECD Report (2003a) points out that the implementation of e-government will aid a number of back office reforms, while alternatively, e-government requires such reforms in order to be successful.

Although of awareness that e-government is more than using ICT and putting public services on the web the impressive growth of e-government exists there in making information and services available to people, as on the other side back office changes have been very slow, ad hoc, and guided by poor planning, inadequate strategic management and weak leadership (Kunstelj and Vintar, 2004). This has resulted in dismal rate of e-government projects, especially in the developing countries. Saboohi and Sushil (2010) realized that there is no wonder that researchers (e.g. Li, 2003, Scholl, 2007) have consistently highlighted that e-government is more an organizational change issue than a technological issue and that the need for managing constant change is central to e-government research.

\section{Change management in e-government implementation}

Change management in software engineering, in particular software evolution as well as change management of 
business processes have been extensively studied, while corresponding methods and tools that support change management of e-government services are still missing at large (Apostolou et al., 2011). E-government services pose unique challenges to change management because they require the co-evolution of the front office service and related back office IT infrastructure (Apostolou et al., 2011). In determination of critical issues in e-government implementation initiatives, there is a strong need to adequately address the change of management issues. Managing e-government is invariably managing change (Saboohi and Sushil, 2010).

Poor change management strategy is one of the causes why the success rate of e-government projects is dismal, especially in developing countries (Kifle and Low Kim Cheng, 2009; Saboohi and Sushil, 2010). In one survey by Heeks (2003), only 15 percent of e-government projects in developing countries are successful, 35 percent are total failures and 50 percent partial failures. Kifle and Low Kim Cheng (2009) analyze core factors of leadership in e-government implementation in twelve ministries in Brunei and identify that poor change management strategy is one area that has been overlooked in Brunei e-government. Government has no strategy how to handle changes brought on by technology, like changes in policy, culture, mindset, organizational structure and process; e.g. simple application of using email system failed as people still treated papers as the only official tool of communication as it has signature on it. Civil servants need to change their thinking and accept e-ways.

Ndou (2004) e.g. points out that change management (especially in e-government implementation) should be divided in change management approach and management of resistance to change. The first refers to change management procedures established within organizations, e.g. identification of bureaucracy, silos, and cultures in the public sector that helps as e-government should revolutionize and reinvent government processes and functions. The second management of resistance to change refers to managing the resistance to change by the employees as this is one of the biggest barriers to a successful change. Sacheva (2009) enumerate numerous causes why people resist changes in e-government implementation, such as long implementation cycle, unknown drivers, lack of clarity of a vision, inadequately support of the top management, the process change, official secrets, un-measurable benefits, disjointed systems and departments, fear of job loss, fears of loss power, changes in job profile, cultural gap, comfort with status quo, work overload, etc.

There has to be emphasized that managing the changes of e-government is very complex not only due to overload so many resistance to change, but also because e-government services are frequently distributed over different IT systems and organizations. Even if they are provided and managed by a single organization, their design and development rely on the collaboration of many people with different roles (Apostolou et al., 2011). Moreover, changes may be triggered by events from outside the public administration such as globalization, new opportunities, pressure of good governance, stakeholders needs, new technology, the e-platform, governments policies and legislation, public-private partnership over which public administration has little or no control (Saboohi and Sushil, 2010).

Although managing changes in e-government implementation is quite hard and complex, some cases of successful change management exist there. Sacheva (2009) provides one example of Kotter's Eight-step Change Model in the National eGovernance Plan (NeGP) program of the Government in India. For initial two years the e-government manager and IT secretary spoke of the need of a comprehensive program. All stakeholders were sensitized to the program and thereafter a team of internal and external consultants were identified. The vision is created and that is "to have all government services accessible to the common man in his locality through a One-Stop-Shop". The vision was presented to the stakeholders and a high powered committee formed of 27 members of parliament. Then the structure was established to make the adoption of e-government permanent. Another example is of Lewin's model and is demonstrated by the Chief Minister who initially unfroze the GoAP (Goal-Oriented Action Planning) employees from their comfort zones by regular and surprise inspections. $\mathrm{He}$ ensured that the message was received so the need to improve services is fully understood. He brought the transition period of 7-8 years to bring change through e-government. After that he unfroze the model through regular video conferences with state government officials and the adoption of paperless office.

\section{Changes that have to be managed in e-government implementation}

Changes in technology bring changes in policy, culture, mindset, organizational structure, and the process (Kifle and Low Kim Cheng, 2009). This claim is consistent with the socio-technical view on organization that regards an organization as a socio-technical system built from two correlated systems - social and technical. The technical system is composed of the processes, tasks, and technologies needed to transform input into output, whereas the social system is composed of people (their believes, skills, values, knowledge, needs), the relationships between them, remuneration systems and authority structures (Bostrom and Heinen, 1977). Every (trans)formation of an organisation as a system must consider these two sub-systems. A return to the classic socio-technical principles provides an environment for successful organisational changes following the implementation of new technologies (Appelbaum, 1997; 
Bostrom and Heinen, 1977). One of the founders of that kind of view on organization (i.e. originating author of Socio-Technical Theory) is Leavitt and his famous diamond that illustrates an organization as a system of people, structure, tasks and technology. Later, the model was extended by other authors (e.g. Kovačič, Jaklič, Indihar Štemberger, and Groznik, 2004) and the fifth entity was added: the organisational culture (Figure 1) and tasks are transformed into processes. These key elements of organisation are interdependent, which means that changes in one of them cause changes in the other. For example, changes in technology cause changes in processes and consequently in people, culture and structure.

\section{Figure 1: Leavitt's Extended Model}

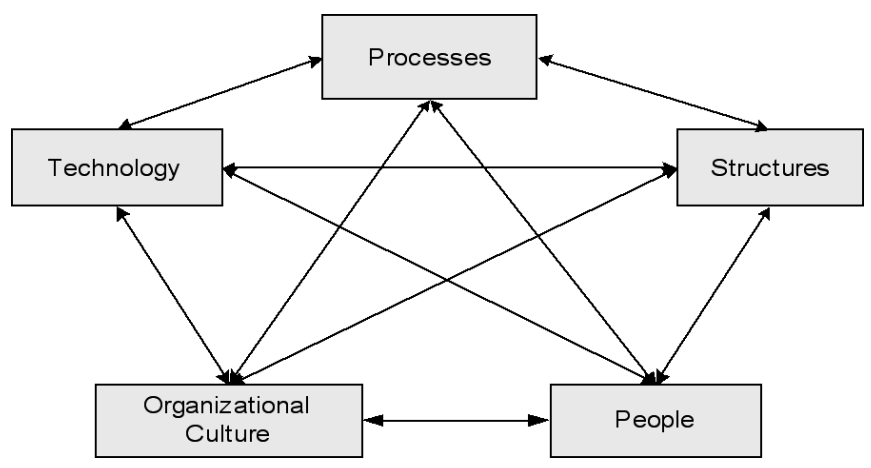

Source: Kovačič et al., 2004, p. 66

The attributes of individual elements of this model are defined by different authors in various ways (e.g. Danziger, Kraemer, Dunkle and King, 1993; Keen, 1981; Lucas and Baroudi, 1994) and are adapted to their own needs.

From the review of existing literature that deals with the relationship between ICT and organizational changes in e-government period, we would try to identify necessary changes of each of the five elements of the extended Leavitt's model and presented them in the Table 1. There exists awareness of that these are not all of the changes that have to be managed in e-government implementation process, but on the other hand we believe that if managers take into an account at least this set of changes, e-government projects would be more successful. Leaders are therefore the most important success factor of managing, realizing and implementing such changes. To manage such complex system with so many changes the new style of leadership is needed in e-government implementation.

\section{New style of leadership as a critical success factor of change management in e-government implementation}

The majority of above mentioned authors from the Table 1 that deals with organizational changes in e-government implementation shares the opinion that one of the precondition for successful transformation of public sector organizations is the role of leadership (e.g. Ho, 2002; O'Donnell, Boyle and Timonen, 2003; Scholl, 2003; Griffin, Foster and Halpin, 2004; Schedler and Schmidt, 2004; Leitner and Kreuzeder, 2005; Elnaghi, Alshawi and Missi, 2007). Althought change management in e-government research is still mising at large, leadership in e-government is currently receiving considerable attention.

Thefirst generation of e-governmentleadersimplementing projects across sectors and levels are pioners. They are tackling the big challenges of e-government and assuming professional risks as they excercise their skills in crossboundary leaderhip. From their experiences they create a set of practices and policies for future generations of e-government leaders (Elnaghi et al., 2007). From their current and further experiences, they have created some lists of competencies that leaders should have for a successful e-government implementation. OECD (2003b) list of essential skills of e-government leaders for dealing with e-government processes apart from basic technical skills, enumerate information management, information society and management skills (Table 2). Enlaghi et al. (2007) provide another e-government leadership competencies, that are divided into three groups - i.e. setting new directions, transforming processes, resource usage, and using information strategicaly (Table 3).

From the above listed competencies and skills of e-government leadership, we can see that skills to drive change in e-government implementation are very complex. Elnaghi et al. (2007) talks about the need of new visionary style of leadership - those who can best help navigate unknown challenges ahead. Leitner and Kreuzeder (2005) further note that e-government calls for strong leadership at different levels to provide a strategic vision and the operational implementation of innovation and change management in public administration. The transformation cannot be made by the public service alone but it requires strong and committed leadership at the political level. Commitment of politicians and public sector managers is crucial in order to manage change. They also talk about new top level leadership (eLeaders) and mid-level leadership (eChampions) that are responsible to drive changes in organizations. Some authors warn that it is important that top public managers do not hand over responsibility for e-government to the professional IT experts (Joyce, 2002; Kifle and Low Kim Cheng, 2009). Kifle and Low Kim Cheng (2009) in studying e-government in Brunei government realize that the way 
Table 1: Necessary changes of individual elements that have to be managed in e-government implementation

\begin{tabular}{|c|c|c|}
\hline Element & Extent of changes & Authors \\
\hline Technology & $\begin{array}{ll}\text { - } & \text { national information infrastructure } \\
\text { - } & \text { network infrastructure and network databases } \\
\text { - } & \text { architecture interoperability } \\
\text { - } & \text { compatible data standards (Extensible Markup Language - XML) } \\
\text { - } & \text { compatible technical standards } \\
\text { - } & \text { implementation of discussion support, multimedia, automation, } \\
& \text { tracking and tracing and personal identification technologies }\end{array}$ & $\begin{array}{l}\text { Lam (2005), Al-kaabi } \\
\text { \& Hattab (2009), } \\
\text { Abulai Alawneh } \\
\text { \& Mohammad } \\
\text { (2010), Saboohi \& } \\
\text { Sushil (2010), Zarei, } \\
\text { Ghapanchi \& Sattary } \\
\text { (2008) }\end{array}$ \\
\hline Processes & $\begin{array}{l}\text { - } \quad \text { changes to the entire process (consideration of business process } \\
\text { change principles from the private sector) } \\
\text { - } \quad \text { significantly accelerated process execution (from a few minutes to a } \\
\text { couple of seconds); process can be executed } 24 / 7 \\
\text { - } \quad \text { horizontal (integration among functions and departments) and } \\
\text { vertical process executions (integration among organisations) } \\
\text { - changes to the rules, which determine the process (trust, safety, } \\
\text { maintenance and integrity must be dealt with therein) }\end{array}$ & $\begin{array}{l}\text { Layne \& Lee (2001), } \\
\text { Scholl (2003), } \\
\text { Elnaghi, Alshawi, \& } \\
\text { Missi (2007), Indihar } \\
\text { Štemberger \& Jaklič } \\
\text { (2007), Kim, Pan \& } \\
\text { Pan, (2007), Klievnik } \\
\text { \& Janssen (2009), } \\
\text { Politt (2010) }\end{array}$ \\
\hline People & $\begin{array}{l}\text { - } \quad \text { the employees must gain a horizontal process view } \\
\text { - } \quad \text { new and complex skills (e.g. self-organisation, confrontation with } \\
\text { - } \quad \text { staff training must be organised, collective learning must be } \\
\text { encouraged } \\
\text { - } \quad \text { leaders must be able to combine their ICT knowledge and skills with } \\
\text { their understanding of the process dimension } \\
\text { - } \quad \text { leaders must beable to develop a strategic vision and comprehensive } \\
\text { human resource management, project management and user- } \\
\text { orientation strategies }\end{array}$ & $\begin{array}{l}\text { Layne \& Lee } \\
\text { (2001), Ho (2002), } \\
\text { O’Donnell, Boyle } \\
\text { \& Timonen (2003), } \\
\text { Griffin, Foster \& } \\
\text { Halpin (2004), } \\
\text { Leitner \& Kreuzeder } \\
\text { (2005), Indihar } \\
\text { Stemberger \& Jaklič } \\
\text { (2007), Kim et al. } \\
\text { (2007) }\end{array}$ \\
\hline $\begin{array}{l}\text { Organizational } \\
\text { Culture }\end{array}$ & $\begin{array}{ll}\text { - } & \text { transition to a service-oriented culture } \\
\text { - } & \text { the employees must overcome departmentalisation thinking } \\
\text { - } & \text { organisational loyalty must be strengthened } \\
\text { - } & \text { employees must be encouraged to perform more challenging tasks, } \\
& \text { to be willing to take responsibility } \\
\text { - } \quad \text { inter-departmental and inter-organisational cooperation and trust } \\
\text { - } \quad \text { must be strengthened } \\
\text { - } \quad \text { the leanderstanding of organisational learning must be strengthened }\end{array}$ & $\begin{array}{l}\text { Ho (2002), } \\
\text { O’Donnell, et al. } \\
\text { (2003), Schedler } \\
\text { \& Schmidt (2004), } \\
\text { Leitner \& Kreuzeder } \\
\text { (2005), Kim, et al. } \\
\text { (2007) }\end{array}$ \\
\hline Structure & 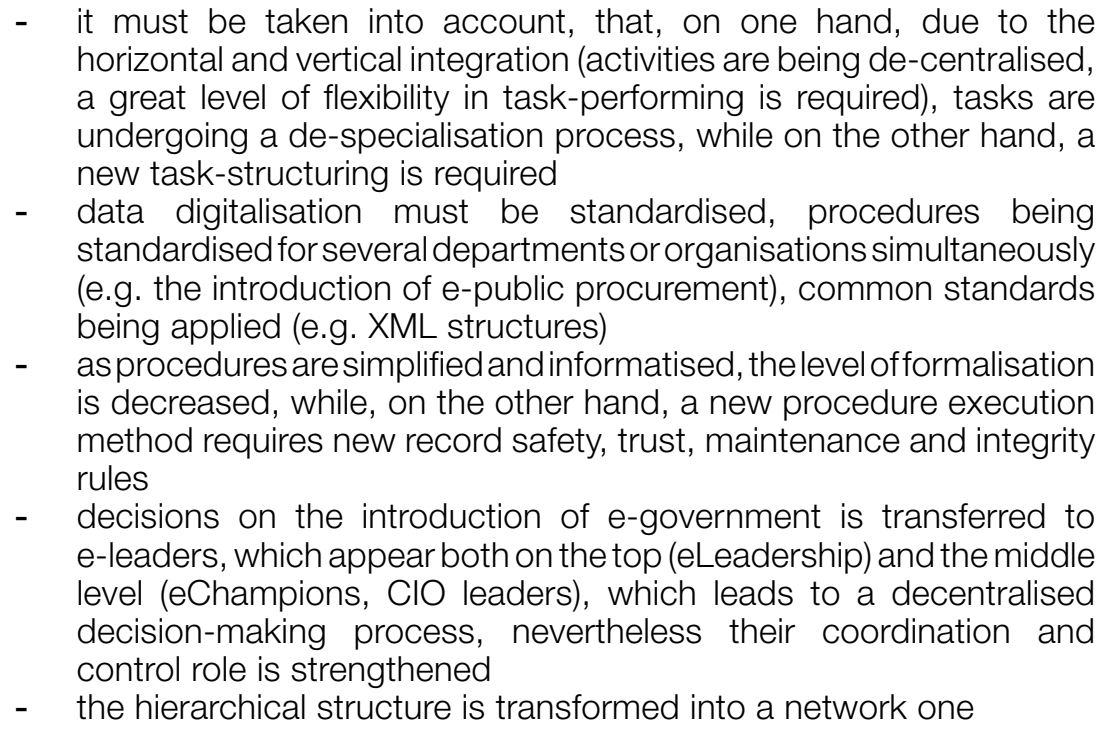 & $\begin{array}{l}\text { Layne \& Lee } \\
\text { (2001), O’Donnell } \\
\text { et al. (2003), Scholl } \\
\text { (2003), Griffin et al. } \\
\text { (2004), Leitner \& } \\
\text { Kreuzeder (2005), } \\
\text { Maniatopoulos } \\
\text { (2005), Kim et al. } \\
\text { (2007), Klievnik \& } \\
\text { Janssen (2009), van } \\
\text { Veenstra, Janssen \& } \\
\text { Tan (2010) }\end{array}$ \\
\hline
\end{tabular}


Table 2: Essential skills for dealing with e-government processes

\begin{tabular}{|c|c|}
\hline Skills & Needed by \\
\hline Information Technology & \multirow[t]{3}{*}{ All employees, managers and IT specialists } \\
\hline Basic IT literacy & \\
\hline Specialist IT skills & \\
\hline Information Management & \multirow{5}{*}{ Managers and IM specialists } \\
\hline Internal information management & \\
\hline External information management & \\
\hline Privacy protection & \\
\hline Feedback mechanisms & \\
\hline Information Society & \multirow{5}{*}{ Managers } \\
\hline Understand capabilities of ICT & \\
\hline Ability to evaluate trends & \\
\hline Foresee ICTs impact on organisational culture & \\
\hline Ability to set ICT strategy & \\
\hline Management/Business & \multirow{7}{*}{ Managers } \\
\hline Organizational change & \\
\hline Risk management & \\
\hline Accountability frameworks & \\
\hline Financing arrangements & \\
\hline Cooperation and collaboration & \\
\hline Public-private partnership & \\
\hline
\end{tabular}

Source: Leitner and Kreuzeder, 2005, p. 213 (from OECD, 2003b)

of e-government implementation in Brunei is bottom-up rather than top-down. Such way is appropriate for the private sector and not for major changes in the public sector. They conclude that innovation in the public sector has to be top-down first and followed bottomup approach. They further point out that poor change management strategy is one of the critical leadership issues in e-government implementation and is too overlooked in Brunei government.

After all discussion of the required new leadership style of managing changes in e-government implementation, there has to be emphasized that the main problem of public managers is that they treated e-government just as "technological mission". However, they have to work on organizational infrastructure if they want to realize full potential of new technologies, especially in achieving joined-up, network government. E.g. Naill Barry, at the Department of Social, Community and Family Affairs in Dublin, considers that building the organizational infrastructure for e-government could take between 12 to 18 months (Joyce, 2002).

\section{Towards a conceptual model of change management in e-government implementation}

\subsection{Role of ICT in e-government period}

In previous two chapters, we have identified some necessary changes that have to be managed in e-government implementation processes and try to define the role of leadership in managing such changes. To identify changes that have to be managed, we use extended Leavitt's organizational model, that regards technology as an equal and co-dependent element in relation to other organizational factors (processes, structure, people and organizational culture). However, the majority of authors during the period of e-government claim that ICT in e-government period has the potential to create radical organisational changes (e.g. Bellamy 
Table 3: E-government leadership competencies

\begin{tabular}{|c|c|}
\hline \multicolumn{2}{|r|}{ Setting new directions } \\
\hline Policy of e-government & Understanding the environment, principles, policies, and foundations \\
\hline Thinking challenges & Applying systems thinking to complex e-government \\
\hline Planning & Planning and organizing strategically for e-government \\
\hline Change & Transforming organizations and cultures to sustain e-government \\
\hline \multicolumn{2}{|r|}{ Transforming processes and resource use } \\
\hline Collaboration & Collaborating across boundaries to achieve e-government goals \\
\hline Architecture and systems & $\begin{array}{l}\text { Understanding and applying effective architecture and enterprise integration for } \\
\text { e-government }\end{array}$ \\
\hline Human capital & Using new models to extend human capital for e-government \\
\hline $\begin{array}{l}\text { Financial resources } \\
\text { investment management }\end{array}$ & Planning and managing funds resources strategically for e-government \\
\hline Performance management & Managing performance-based e-government programs and projects \\
\hline $\begin{array}{l}\text { Execution/implementati- } \\
\text { on }\end{array}$ & Moving from concept to reality \\
\hline \multicolumn{2}{|r|}{ Using information strategically } \\
\hline $\begin{array}{l}\text { Information and } \\
\text { knowledge resources }\end{array}$ & $\begin{array}{l}\text { Providing the right information and knowledge at the right time within and across } \\
\text { boundaries }\end{array}$ \\
\hline Security and privacy & Balancing security, privacy, access issues, and protection of information \\
\hline Technologies & Understanding strategic uses of information through the use of technologies \\
\hline
\end{tabular}

Source: Elnaghi et al., 2007, pp. 8-9

and Taylor, 1998; Ho, 2002; COM, 2003; Bekkers, 2003) and regards ICT as the key, more or less independent element of organizational transformation. On the other side, there are authors there who believe that ICT is only one of the elements within an organisation, which is reciprocally related to other elements within as well as outside of the organisation, and the only appropriate connection between them enables optimum exploitation of the potentials of new technologies (e.g. Fountain, 2001; Van Wert, 2002; Maniatopoulos, 2005). The latter group of authors hold socio-technical view on organization, presented in Leavitt's model.

After confrontation those two views of ICT role in e-government period our opinion is that ICT in e-government period is a key driver of organizational transformation of public sector organizations, however, we are also aware that it more than ever depends upon other factors within an organisation, and partly upon its surroundings, because such factors are usually those that trigger potentials of ICTs and enable or even limit their optimum realization. Therefore, we adjusted Leavitt's model into a model that enables ICT to be placed into the centre of the socio-technical system as the main transformation factor in public sector organisations.
ICT is a central actor in such model; however, it cannot operate independently. An optimum potential realization is strongly co-dependent on the other elements of the model. This leads to the creation in some ways of a new model, which would best describe the relationships among the key factors for a successful e-government implementation (Figure 2).

Figure 2: Model Representing the Role of ICT in the E-Government Period in Relation to other Organizational Factors

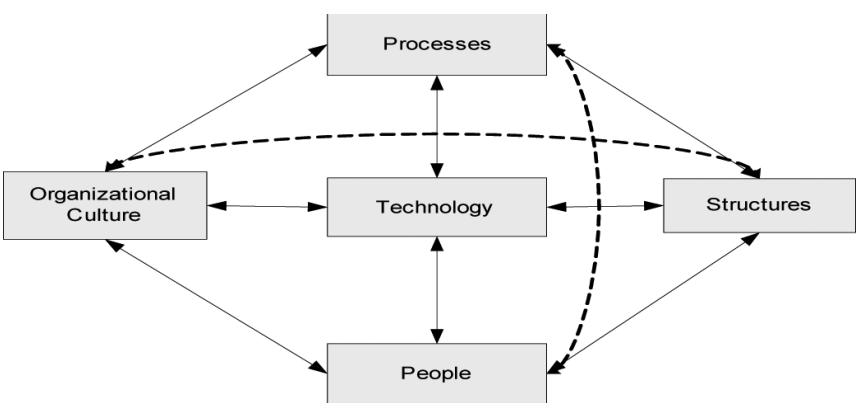


Therefore, changes brought by new technologies and their potentials into e-government processes have to be into the core of change management strategy and changes in other four elements of organization that are caused by technology have to be addressed at the same time and relations among them have to be identified.

New type of leadership with a complex vision, integrating the reengineering of work processes, organizational structures, and cultures also have to bear in mind that new technologies and the Internet are at the core of their competencies (Leitner and Kreuzeder, 2005), i.e. those that are listed in Table 2 and Table 3.

\subsection{Change management model in e-government implementation}

On above presented assumptions, we would try to create conceptual change management model of e-government implementation (Figure 3) in which in the centre we positioned our adjusted model representing the role of ICT in the e-government period in relation to other organizational factors (Figure 2). All changes that occurred in each of the element of the adjusted model (see Table 1) have to be managed and included in comprehensive change management strategy. Those changes have to be managed by e-government leaders that have to conquer adequate skills to manage them (see Table 2 and Table 3 ) and select the most appropriate change management model (as presented in Chapter 2) that is suitable for their particular organization.

However, in implementing such changes there exist some changes that have to be addressed more specifically and need special attention. As it has been acknowledged from the existing literature, the most undesirable changes in e-government period are those in the organizational structure. Maniatopoulos (2005) e.g. finds that the structural arrangement of local administrations is the main challenge in introduction an e-procurement system into British local administration. Semi-autonomous units are based upon specialised services and are run by higher managers, intense rivalry and lack of cooperation. The change process is thus strongly affected by traditional structures. Li (2009) further realized that, despite large investments into technology, at the point of e-government implementation into the Chinese public administration, its structure remained essentially bureaucratic, based on standardised coordination and control procedures. The main challenge is thus how to apply this technology for achieving changes into the organisational structure towards an improved decentralisation and decreased formalisation. During the introduction of globally adopted accountingstandardsforlegallyrequiredfinancialaccounts for Dutch companies, van Veenstra, Janssen and Tan (2010) find that despite projections that a standardised procedure was to promote the creation of a network structure, decrease the number of hierarchical levels and increase the horizontality level, no network structure has emerged, an additional control step has been added and the government has retained its dominant process control role and has even strengthened the supervisory role, which means that decision-making has been further centralised. The closed structure prevents the steering body from steering between organisations.

Predictions and visions of ICT as a bureaucracy reformation tool, that decreasing the number of

Figure 3: Change Management Model of E-Government Implementation

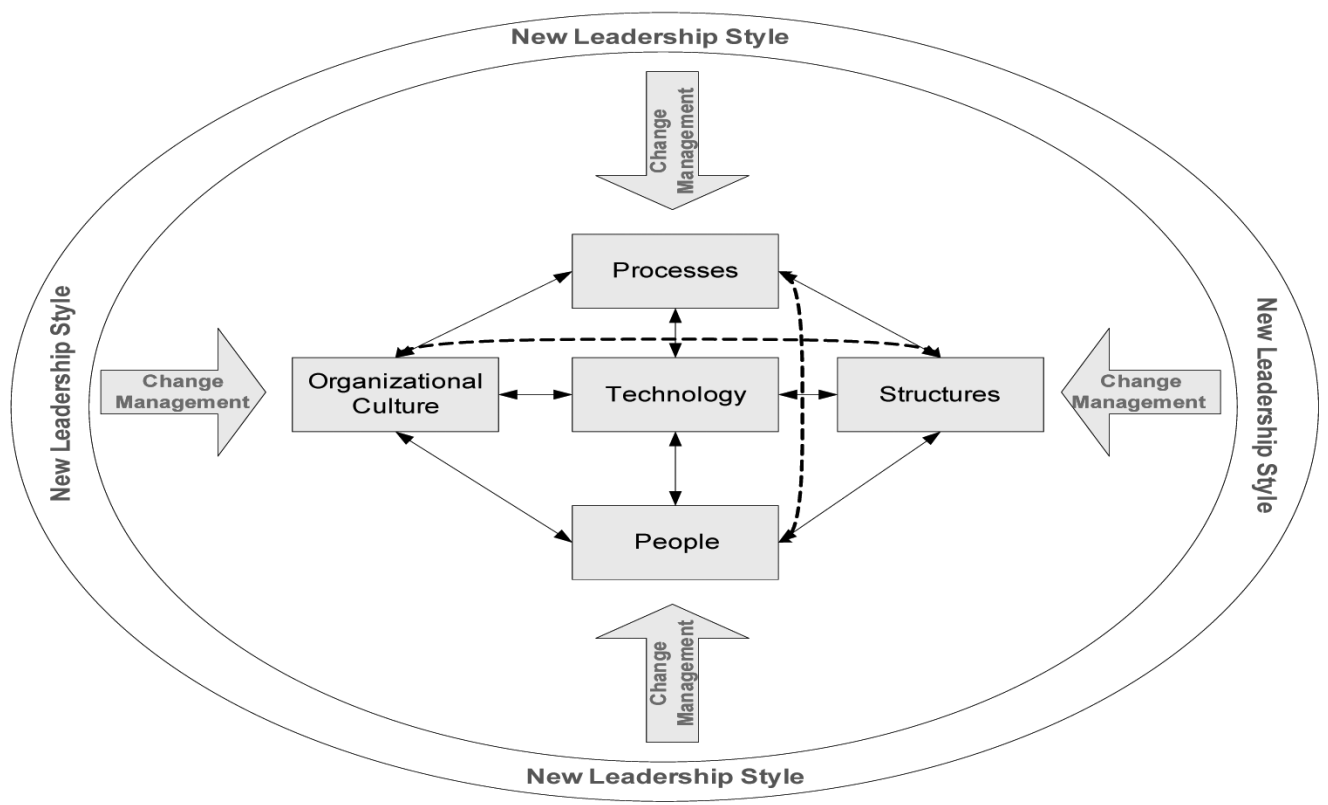


hierarchical levels, transforming a hierarchical structure into a network one, decentralising activities and developing new horizontally linked and strategically independent agencies are therefore so far behind of its realization in practice.

Organisational culture is also regarded by some authors as the main obstacles for poor realization of ICTs potentials. Maniatopoulos (2005) thinks that the greatest challenge in introducing new technologies is the dominant organisational culture, which requires a different way of thinking. He reports that, at the introduction of XML standards into e- procurement procedures, organisations did not show great enthusiasm for the introduction of such structures and that the employees still tend to execute the procedure manually. Also Klievnik and Janssen (2009) saw changes in culture as one of the obstacles and conditions for transitioning to higher levels of joinedup government in Dutch public sector organisations.

The processes itself are most subjected to ICT's influences and potential. Many positive experiences related to the changes there were reported already during the earliest I(C)T implementation periods. A rather significant number of authors reports on an increased process efficiency during the e-government period, mainly in terms of shortening the required time for executing a process, (Kim et al., 2007; Moon, 2002; Pollitt, 2010) standardizing procedures (Maniatopoulos, 2005; Pollitt, 2010) and facilitating and improving information management and exchange (Indihar Štemberger and Jaklič, 2007) but problems occur when a horizontal (integration among functions and services) and vertical (integration among organisations) process execution is required. In his analysis of U.S. municipal administrations, Moon (2002) finds that most administrations have reached Level 1 or 2 in service development (one- or two-way interaction), but none have been able to reach Level 4, which requires vertical and horizontal integration. Groznik and Trkman (2009) link the unsuccessful completion of the e-procurement implementation in Slovenia to an inadequate business processes reengineering for reasons of insufficient horizontal integration. Klievnik and Janssen (2009), in their analysis of progress towards a joined-up government, which requires the linkage among several organisations and departments, find that most Dutch public sector organisations have reached Level 2 - integrated organizations (on which services and information technologies have been linked on the level of the given organisation), but still have a lot of work to do until reaching Level 4 or 5 (inter-organisational integration and joined-up government). Li (2009) reports that, despite huge investments into e-government technologies in China, the expected process changes have not been achieved for reasons of non-integration among organisations and within organisations themselves.

As it has been seen from above mainly unsuccessful introduction of changes in e-government implementation processes, public sector organizations are still far behind of introduction of changes that are listed in Table 1. Majority of above mentioned authors, who analyze introduction of such changes in e-government implementation found reasons for unreached expectations in inadequate management support. Maniatopoulos (2005) finds that management regards the introduction of e-procurement primarily as a procedure standardisation and public procurement practice process and not as management issue. A lack of project management is one of the main reasons for the rather unsuccessful introduction of e-procurement in Slovenia (Groznik and Trkman, 2009) Similarly, Klievnik and Janssen (2009) through analysing the progress towards a joined-up Dutch governments, where most organisations can be found on the starting levels, found that project management and leaders have to play an ever-increasing role in achieving higher levels. Moon (2002) regards the implementation of e-government into US municipal administrations as rather unsuccessful and finds that professional leaders are more inclined towards innovations than political ones.

There is no doubt, that successful introduction of changes in e-government requires interdisciplinary approaches and leaders who are able to combine their ICT knowledge with their understanding of the process dimension (Griffin et al., 2004). The awareness must be strengthened that e-government calls for strong leaders at various levels. A new top management (eLeadership) and new middle management (eChampions) are required, who will be able to develop a strategic vision and execution of changes in the e-government processes. On the other hand, the transformation cannot be made by the public service alone but requires strong and committed leadership at the political level. Commitment of politicians and public sector managers are crucial in order to manage change. (Leitner and Kreuzeder, 2005). Elnaghi et al. (2007) who place emphasis upon the role of leading figures in an organisation as the key actors for a successful e-government implementation, warn that lack of authority is the main obstacle towards the development of e-government, which is regarded by leaders as a technological mission and not as a strategic vision.

As there have been acknowledged so many unsuccessful introductions of changes in e-government, the idea of Ndou (2004) who points out that change management (especially in e-government implementation) should be divided in change management approach and management of resistance to change should be in the place and have to be included in change management strategy.

Proposed change management model is as far behind of its realization, but considering so many unsuccessful introductions of changes in the past, the main barriers 
could be identified and change management strategies have to offer solutions to pass through of them.

\section{Conclusion and further research}

As we emphasized in the previous chapters, managing changes in e-government implementation is a very complex task and that, on the other side, poor change management strategy is one of the causes why e-government projects frequently failed. From the review of the existing literature, it is clear that change management issues in e-government research are still missing at large and that this gap is probably a consequence of poor addressing such issues in practice. One of the causes for that could be found also in prevailing view of e-government as an application of ICT in public sector and not as a complex organizational issue. One of the biggest responsibilities of insufficient addressing change management issues stand on the leadership of e-government that hand over responsibility for e-government to the professional IT experts instead of preparing strategic planning and considerable change management strategy for e-government. It must become clear that e-government is more an organizational change issue than a technological issue.

Through our discussion and the proposed model for change management in e-government implementation, we would try to address some important issues that are currently missing and that have to be taken into an account for more successful e-government implementation. At the same time, we are aware of that our model could be improved and more importantly, verified in practice.

\section{References}

1. Abuali, A., Alawneh, A., \& Mohammad, H. (2010). Factors and Rules Effecting in E-Government. European Journal of Scientific Research, 39(2) , 169-175.

2. Al-kaabi, R., \& Hattab, E. (2009). E-Government Success Factors: A Survey. Proceedings of The 9th European Conference on e-Government, (pp. 3944). University of Westminster, London.

3. Apostolou, D., Mentzas, G., Stojanovic, L., Thoenssen, B., \& Pariente Lobo, T. (2011). A collaborative decision framework for managing changes in e-Government services. Government Information Quarterly, 28 , 101-116.

4. Appelbaum, S. (1997). Socio-technical systems theory: an intervention strategy for organizational development. Management Decision, 35(6) , 452463.
5. Bannister, F., \& Connolly, R. (2011). Trust and transformational government: A proposed framework for research. Government Information Quarterly , Article in Press.

6. Beatlle, A. W. (2009). Proceedings of the WebSci'09: Society On-Line. Is web-based interaction reshaping the organizational dynamisc of public administration?: A comparativeempirical study on eGovernment.

7. Bekkers, V. (2003). E-government and the emergence of virtual organizations in the public sector. Information Polity, 8(3/4) , 89-102.

8. Bellamy, C., \& Taylor, J. (1998). Governing in the Information Age. Buckingham: Open University Press.

9. Bosilj-Vukšić, V. (2011). Change Management as a Critical Success Factor (CFS) of Business Process Management (BPM) Projects. Presentation on Doctoral Seminar in Information Management, FELU, Ljubljana.

10. Bostrom, R., \& Heinen, J. (1977). MIS Problems and Failures: A Socio-Technical Perspective. MIS Quarterly, 1(3) , 17-32.

11. Danziger, J. N., Kraemer, K. L., Dunkle, D. E., \& King, J. L. (1993). Enhancing the Quality of Computing Service: Technology, Structure, and People. Public Administration Review, 53(2) , 161-169.

12. Dias de Lima, J. (2009). Managing Change: Winning Hearts and Minds. Harvard Business Publishing .

13. Elnaghi, M., Alshawi, S., \& Missi, F. (2007). A Leadership Model for e-Government Transformation. Proceedings of European and Mediterranean Conference on Information Systems 2007 , 1-12.

14. European Commission. (2003) - COM, 2003: The role of eGovernment for Europe's future, 567 final. European Commision.

15. Fountain, J. (2001). Building the virtual state. Information technology and institutional change. Washington D.C.

16. GAO-01-959T Electronic Government. (2001). ELECTRONIC GOVERNMENT-Challenges Must Be Addressed With Effective Leadership and Management. United States General Accounting Office.

17. Griffin, D., Foster, A., \& Halpin, E. (2004). Joinedup E-government: an exploratory study of UK local 
government progress. Journal of Information Science and Technology , 58-83.

18. Groznik, A., \& Trkman, P. (2009). Upstream supply chain management in e-government: The case of Slovenia. Government Information Quarterly , 459467.

19. Heeks, R. (2003). E-government for development: Success and failure rates of e-government in developing/transitional countries: Overview.

20. Heeks, R. (2000). Reinventing Government in the Information Age. Roultedge Press, London.

21. Hiatt, J. (2010). ČThe definition and history of change management«.

22. Ho, A. T.-K. (2002). Reinventing Local Governments and the E-Government Initiative. Public Administration Review, 62(4) , 434-444.

23. Indihar Štemberger, M., \& Jaklič, J. (2007). Towards E-government by business process change - A methodology for public sector. International Journal of Information Management , 221-232.

24. Jansen, A. (2005). Assessing E-government progress - why and what. . NOKOBIT 2005. ISBN 82-8033026-7. University of Oslo, Norway : Tessem, B.; Iden, J.; Cristensen, G. (eds).

25. Joyce, P. (2002). E-government, strategic change and organisational capacity. V E. M. Milner, Delivering the Vision. Public services for the information society and the knowledge economy. (pp. 156-171). London: Routledge.

26. Keen, G. (1981). Information Systems and Organizational Change. Communications of the ACM, 24(1) , 24-33.

27. Kifle, H., \& Low Kim Cheng, P. (2009). e-Government Implementation and Leadership - the Brunei Case Study . Electronic Journal of e-Government Volume, 7(3) , 271-282.

28. Kim, H. J., Pan, G., \& Pan, S. L. (2007). Managing IT-enabled transformation in the pubic sector: A case study on e-government in South Korea . Government Information Quarterly , 338-352.

29. Klievnik, B., \& Janssen, M. (2009). Realizing joinedup government - Dynamic capabilities and stage models for transformation. Government Information Quarterly , 275-284.

30. Kovačič, A., Jaklič, J., Indihar Štemberger, M.,
\& Groznik, A. (2004). Prenova in informatizacija poslovanja. Ljubljana : Ekonomska fakulteta.

31. Kunstelj, M., \& Vintar, M. (2004). Evaluating the progress of e-government development: A critical analysis. Information Polity, 131-148.

32. Lam, W. (2005). Barriers to e-government integration. The Journal of Enterprise Information Management, 18(5) , 511-530.

33. Layne, K., \& Lee, J. (2001). Developing fully functional E-government: A four stage model. Government Information Quarterly , 122-136.

34. Leitner, C., \& Kreuzeder, M. (2005). Organisational Changes, Skills and the Role of Leadership Required by eGovernment. EGOV 2005, LNCS 3591, M.A. Wimmer et al. (Eds.) , 210-217.

35. Li, F. (2003). Implementing e-government strategy in Scotland: current situations and emerging issues. Journal of Electronic Commerce in Organizations, $1(2), 44-45$.

36. Li, Z. (2009). How E-government affects the organisational structure in Chinese government. Al \& Soc , 123-130.

37. Lucas, H. C., \& Baroudi, J. (1994). The Role of Information Technology in Organization Design. Journal of Management Information Systems, 10(4) , 9-23.

38. Maniatopoulos, G. (2005). E-government Movements of Organizationall Change: A Social Shaping Approach. 4th International Critical Management Studies Conference, Judge Institute of Management, Cambridge, UK .

39. Moon, M. J. (2002). The Evolution of E-Government among Municipalities: Rhetoric or Reality? Public Administration Review, 62 (4) , 424-433.

40. Ndou, V. (2004). 'E-government for developing countries: Opportunities and challenges'. The Electronic Journal on Information Systems in Developing Countries, 18,1 -24.

41. O'Donnell, O., Boyle, R., \& Timonen, V. (2003). Transformational aspects of E-government in Ireland: Issues to be addressed. Electronic Journal of e-Government , 23-32.

42. OECD. (2003a). OECD E-Government Flagship Report ČThe E-Government Imperative«. Paris: Public Management Committee, OECD. 
43. OECD. (2003b). Policy Brief, Checklist for eGovernment leaders.

44. Pollitt, C. (2010). Technological Change: a cenral yet neglected feature of pubilc administration. NISPA10 (Version 30-04-2010). Ljubljana.

45. Saboohi, N., \& Sushil. (2010). Managing continuity and change: a new approach for strategizing in e-government. Transforming Government: People, Process and Policy, 4(4) , 338-364.

46. Sacheva, S. (2009). Change Management for e-Governance. I-Ways Journal of E-Government Policy and Regulation 32, IOS Press , 109-117.

47. Schedler, K., \& Schmidt, B. (2004). Managing the e-government organization. International Public Management Review , 1-20.

48. Scholl, H. (2007). Central research question in e-government, or which trajectory should the study domain takes? Transforming Government: People, Process and Policy, 1(1) , 67-88.

49. Scholl, J. (2003). E-government: A Special Case of ICT-enabled Business Process Change. 36th Hawaii International Conference on System Sciences, (pp. 1-12).

50. van Veenstra, A., Janssen, M., \& Tan, Y.-H. (2010). Towards an Understanding of E-Government Induced Change - Drawing on Organization and Structuration Theories. EGOV 2010, LNCS 6228 (pp. 1-12). Wimmer, M. A.; et al. (eds).

51. Van Wert, J. (2002). Questions about E-Government,Digital Government Workshop at the Kennedy School of Government, Harvard University.

52. Zarei, B., Ghapanchi, A., \& Sattary, B. (2008). Toward national e-government development models for developing countries: A nine-stage model. The International Information \& Library Review, 40 , 199207.
Janja Nograšek is a young researcher on the Faculty of Administration, University of Ljubljana, Slovenia, and a PhD student on the Faculty of Economics, University of Ljubljana, Slovenia. Her research interests include organizational change in e-government implementation, new organizational models in e-government period, role of ICT in e-government period and e-government benchmarking. She also participates in project about efficient and effective public administration in Slovenia in relation to EU and in other projects of e-government in Slovenia. 